\title{
A Study on the Generation of Cyber Chinglish Blend Words From the Perspective of Construction Coercion*
}

\author{
WEI Ning-ling \\ Leshan Normal University, Sichuan, China
}

\begin{abstract}
Chinglish blend words, as the most creative type of cyber language, have been widely spread to Chinese people's daily life and have a great effect on the generation of English words. This essay is intended to study how cyber Chinglish blend words are generated. The theory of construction indicates that " $\mathrm{C}_{\text {blend }}$ " is created by integrating a construction $C_{1}$ into a bigger construction $C_{2}$ and it is essentially $C_{2}$ with a conflict between form and meaning. The suppression of its conflict is realized by construction coercion, which ensures that the semantic specifications conform to its grammatical structure. The generating process shows that conflict is the motive power to construction coercion which in turn suppresses conflicts.
\end{abstract}

Keywords: cyber Chinglish blend words, construction, construction coercion

\section{Introduction}

Recently it is quite common to find such foreign words as "ungelivable”, “newbility”, "smilence” and "eggache” being widely used in internet or even being occasionally spoken in daily life. If inquired more carefully, these words resemble the spelling rules of English words and hold a certain semantic resemblance with Chinese characters. Then, there come the questions: what are these words? How are they generated?

\section{Cyber Chinglish Blend Words}

Being influenced by Chinese Language and cultures, Chinglish is commonly applied to ungrammatical or nonsensical English in Chinese contexts (Nury Vittachi, 2000).

Chinglish has a long history but it is through Internet that it is widely spread and applied. Recently, a large number of cyber Chinglish words are generated on Internet and even spread to Chinese people's daily life. These words could be Chinese-involved words like "ungelivable”, "newbility”, “unkaoable”, "zhuangbility”, "shability”, “eggache”, or blend words like "smilence”, “divoice”, "vegeteal”, “sextary”, “suihide”, or even English sentences as "Long time no see”, "I will give you some color to see see”, "Good good study, day day up”, which are externally formed in English but internally endowed with Chinese meaning. Among them, blend words are the most popular and innovative ones, which will be focused in this study in particular.

Unlike compound word which is combined merely by two words, blend word is one formed from parts of two or more other words with a certain change in spelling if necessary. Current popular cyber Chinglish blend words include “sextary”, “togayther”, “smilence”, “jokarlist”, “emotionormal”, “suihide”, “stupig”, and

\footnotetext{
* Acknowledgements: Web Culture Project Sponsored by the Humanities and Social Science Research Base of the Sichuan Provincial Education Department (Project No.: WLWH16-13).

WEI Ning-ling, lecturer, master, School of Foreign Languages, Leshan Normal University, Sichuan, China.
} 
"Chinsumer”. How can these English words be integrated with Chinese meaning? This essay will focus on this question from the perspective of construction coercion.

\section{The Construction of Cyber Chinglish Blend Words}

According to Goldberg (1995), a distinct construction is defined to exist when one or more of its formal or semantic properties are not strictly predictable from knowledge of the component parts of the construction itself and existence of other constructions in the grammar: " $\mathrm{C}$ is a Construction iffdef $\mathrm{C}$ is a form-meaning pair $<\mathrm{Fi}$, $\mathrm{Si}>$ such that some aspects of $\mathrm{Fi}$ or some aspects of $\mathrm{Si}$ is not strictly predictable from C's component parts or from other previously established constructions” (Goldberg, 1995, p. 4).

As for a Chinglish blend word which is formed from parts of two or more other words, its construction meaning cannot be merely predicted from its components or pre-existing constructions. For example, the meaning of "sextary" is not simply the semantic addition of "sex" and "-tary" but is endowed with extra semantic indication. Therefore, Chinglish blend word can be counted as a construction, which is marked here as $\mathrm{C}_{\text {blend }}<\mathrm{Fi}_{\text {blend, }} \mathrm{Si}_{\text {blend }}>$. As words and even morphemes are categorized into construction (Langacker, 2007), Chinglish blend word can be regarded as recombination of two constructions of words (marked here as $\mathrm{C}_{1}$ and $\mathrm{C}_{2}$ ) in forms (marked here as $\mathrm{Fi}_{1}$ and $\mathrm{Fi}_{2}$ ) resulting in a new form $\mathrm{Fi}_{\text {blend }}$ with a new meaning $\mathrm{Si}_{\text {blend. }}$ As for the generating process, there is a question: How are $\mathrm{Fi}_{\text {blend }}$ and $\mathrm{Si}_{\text {blend }}$ paired?

\section{Generation Condition: Construction Coercion}

Since Chinglish blend word is formed from parts of two words, on the morpheme level, it can be regarded as the combination of two morphemes. By further analyzing the constituents of the popular cyber Chinglish blend words, it can be found that these words are formed in the way of replacing a morpheme (marked here as the replaced) of one word by the other word (marked here as the replacer) with a slight change in the form if necessary. The analysis of their constituents is listed in Table 1.

Table 1

The Analysis of Constituents

\begin{tabular}{lll}
\hline Blend words & The replaced & The replacer \\
\hline sextary & secre- & sex \\
togayther & -ge- & gay \\
jokarlist & journa- & joker \\
emotionormal & -al & normal \\
suihide & -cide & hide \\
stupig & -pid & pig \\
chinsumer & con- & chin \\
\hline
\end{tabular}

The comparison of the replacer and the replaced indicates that both of them are similar in form and pronunciation. From the perspective of construction, these words $\left(\mathrm{C}_{\text {blend }}\right)$ are created by integrating a construction $\left(\mathrm{C}_{1}\right)$ into a bigger construction $\left(\mathrm{C}_{2}\right)$. Therefore, to some extent, $\mathrm{C}_{\text {blend }}$ is intended to imitate the original construction $\mathrm{C}_{2}$ on the phonetic level. On the aspect of form, $\mathrm{Fi}_{\text {blend }}$ is phonetically organized. Then, there is a question: How are $\mathrm{Si}_{\text {blend }}$ and $\mathrm{Fi}_{\text {blend }}$ paired? What do $\mathrm{Si}_{1}$ and $\mathrm{Si}_{2}$ have to do with $\mathrm{Si}_{\text {blend? }}$ ?s it the simple semantic addition of both? The internal relationship between $\mathrm{Si}_{1}$ and $\mathrm{Si}_{2}$ will be further analyzed in Table 2. 
Table 2

The Analysis of Siblend

\begin{tabular}{lll}
\hline C blend & \multicolumn{2}{c}{$\mathrm{Si}_{\text {blend }}$} \\
\cline { 2 - 3 } $\begin{array}{ll}\text { sextary } \\
\text { togayther }\end{array}$ & The physical activity by which the people can produce young & $\mathrm{Si}_{2}$ \\
jokarlist & Homosexual men & Therson who is employed to do office work \\
emotionormal & The person who likes making jokes & The person whose job is to collect news \\
suihide & A situation in which the people have strong feelings & Usual and ordinary \\
stupig & Go somewhere where you cannot easily be found and seen & Kill oneself \\
chinsumer & Someone who is greedy and mean & Showing a lack of intelligence \\
\hline
\end{tabular}

According to the comparison between $\mathrm{Si}_{1}$ and $\mathrm{Si}_{2}$ in each word, the combing of both leads to a certain conflict. For instance, secretary is a serious profession without any relation to sex performance; homosexual is forbidden in most countries in the world without any expectation of being together forever; journalist is the person who should be objective and serious in reporting but never a joker; You can never be emotional and at the same time keep normal; committing suicide can happen at any occasion but why it has to be done by hiding; pig refers to the person who is greedy and mean but not certainly stupid; in the world anyone who buys things or use services can be called consumer but should not be restricted to the purchasers in China. These semantic conflicts between $\mathrm{Si}_{1}$ and $\mathrm{Si}_{2}$ indicate a fact that certain conflicts exist between form and meaning of $\mathrm{C}_{\text {blend }}$, or $\mathrm{C}_{\text {blend }}$ is $\mathrm{C}_{2}$ with a conflict between its form and meaning. Thus, in order to make the new construction $\mathrm{C}_{\text {blend }}$ reasonable, the conflict has to be suppressed. This process is called construction coercion by Michaelis (2003), who stated that "If lexical and structural meaning conflict, the semantic specifications of the lexical element conform to those of the grammatical structure with which that lexical item is combined” (p. 172).

In order to suppress the conflict, lexical meaning have to conform to the grammatical structure and a certain relation has to be created between $\mathrm{Si}_{1}$ and $\mathrm{Si}_{2}$. Since these blend words are created on Internet with Chinese cultural background, it indicates that $\mathrm{Si}_{1}$ should not be explained literally in English but with Chinese connotations. Thus, $\mathrm{Si}_{1}$ is integrated into $\mathrm{Si}_{2}$ by being involved with Chinese workplace characteristic as in "sextary" who is not morally devoted to her profession and "jokarnist" who is untrustworthy; or with its character of Chinese economy as in "Chinsumer" who refers especially to the Chinese consumer with great purchasing power; or with an injustice case in China as in "suihide" which cunningly covers up the fact that the innocent was murdered but not committed suicide during the game of playing hide and seek; or with Chinese language connotation as in "stupig" in which pig refers to the unwise person.

\section{Conclusion}

Conflict is the motive power to construction coercion which in turn suppresses conflicts. The greater the conflict is, the greater the construction coercion is. The cultural gap between Chinese and English generates the conflict between $\mathrm{Si}_{1}$ and $\mathrm{Si}_{2}$. The bigger the gap is, the greater the conflict is. Thus, in order to suppress the conflict, greater construction coercion power is needed and more cognitive efforts have to be extracted.

\section{References}

Goldberg, A. E. (1995). Constructions: A Construction Grammar Approach to Argument Structure. Chicago and London; The University of Chicago Press. 
Langacker, R. W. (2007). Ten lectures on cognitive grammar by Ronald Langacker. Beijing: Foreign Language Teaching and Research Press.

Michaelis, L. (2003). Word meaning, sentence meaning, and syntactic meaning. In C. Hubert, R. Dirven, and J. Taylor (Eds.), Cognitive approaches to lexical semantics. Berlin/New York: Mouton de Gruyter.

Nury Vittachi. (2000). Chinglish in the oral work of non-English majors archived wayback machine from Yinglish to sado-mastication. World Englishes, 19(3), 405-414. doi:10.1111/1467-971X.00189 